\title{
Load-bearing capacity of CAD/CAM 3D-printed zirconia, CAD/CAM milled zirconia, and heat-pressed lithium disilicate ultra-thin occlusal veneers on molars
}

\author{
Ioannidis, A ; Bomze, D ; Hämmerle, C H F ; Hüsler, J ; Birrer, O ; Mühlemann, S
}

\begin{abstract}
OBJECTIVES: The load-bearing capacity of ultra-thin occlusal veneers made of 3D-printed zirconia were compared to the ones obtained by fabricating these reconstructions by CAD/CAM milling zirconia or heat-pressing lithium-disilicate. METHODS: On 60 extracted human molars, the occlusal enamel was removed and extended into dentin. Occlusal veneers of $0.5 \mathrm{~mm}$ thickness were digitally designed. The specimens were divided into 3 groups $(\mathrm{n}=20$ each) differing in the restorative material and the fabrication technique of the occlusal veneer. (1) 3DP: 3D-printed zirconia (Lithoz); (2): CAM: milled zirconia (Ceramill Zolid FX); (3) HPR: heat-pressed lithium disilicate (IPS e.max Press). After conditioning procedures, the restorations were adhesively bonded onto the conditioned tooth. Thereafter, all specimens were aged in a chewing simulator by exposure to cyclic fatigue and temperature variations. Subsequently the specimens were statically loaded and the load which was necessary to decrease the maximum load by $20 \%$ and initiate a crack $\left(\mathrm{F}_{\text {initial }}\right)$ and the load which was needed to fracture the specimen $\left(\mathrm{F}_{\max }\right)$ were measured. Differences between the groups were compared applying the KruskalWallis (KW) test and the Wilcoxon-Mann-Whitney-Test (WMW: $\mathrm{p}<0.05)$. RESULTS: The median $\mathrm{F}_{\text {initial }}$ values for the groups 3DP, CAM and HPR were 1'650 N, 1'250 N and $500 \mathrm{~N}$. The differences between all three groups were statistically significant $(\mathrm{KW}: \mathrm{p}<0.0001)$. The median $\mathrm{F}_{\max }$ values amounted to 2'026 $\mathrm{N}$ for the group 3DP, 1'500 $\mathrm{N}$ for the group CAM and 1'555 $\mathrm{N}$ for the group HPR. Significant differences were found between 3DP and CAM (WMW: $\mathrm{p}=0.0238$ ). SIGNIFICANCE: Regarding their load-bearing capacity, 3D-printed or milled zirconia, as well as heat-pressed lithium disilicate, can be recommended as restorative material for ultra-thin occlusal veneers to prosthetically compensate for occlusal tooth wear. Despite statistically significant differences between the restoration materials, all load-bearing capacities exceeded the clinically expected normal bite forces.
\end{abstract}

DOI: https://doi.org/10.1016/j.dental.2020.01.016

Posted at the Zurich Open Repository and Archive, University of Zurich

ZORA URL: https://doi.org/10.5167/uzh-187750

Journal Article

Submitted Version

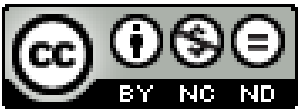

The following work is licensed under a Creative Commons: Attribution-NonCommercial-NoDerivatives 4.0 International (CC BY-NC-ND 4.0) License.

Originally published at: 
Ioannidis, A; Bomze, D; Hämmerle, C H F; Hüsler, J; Birrer, O; Mühlemann, S (2020). Load-bearing capacity of CAD/CAM 3D-printed zirconia, CAD/CAM milled zirconia, and heat-pressed lithium disilicate ultra-thin occlusal veneers on molars. Dental Materials, 36(4):e109-e116.

DOI: https://doi.org/10.1016/j.dental.2020.01.016 


\section{Load-bearing capacity of CAD/CAM 3D-printed zirconia, CAD/CAM milled zirconia, and heat-pressed lithium disilicate ultra-thin occlusal veneers on molars}

Ioannidis $A^{a}$, Bomze $D^{b}$, Hämmerle $\mathrm{CHF}^{a}$, Hüsler $\mathrm{J}^{\mathrm{c}}$, Birrer $\mathrm{O}^{\mathrm{d}}$, Mühlemann $\mathrm{S}^{\mathrm{a}}$

Keywords: ceramics, 3D printing, zirconia, dental porcelain, lithium-disilicate ceramic, computer-aided design, computer-aided manufacturing, occlusal dental veneers, fatigue

Address for correspondence:

Dr. med. dent. Alexis loannidis

Clinic of Fixed and Removable Prosthodontics and

Dental Material Science

Center of Dental Medicine, University of Zurich

Plattenstrasse 11

$\mathrm{CH}-8032$ Zurich, Switzerland

Phone: +41446340404

E-Mail: alexis.ioannidis@zzm.uzh.ch

a Clinic of Fixed and Removable Prosthodontics and Dental Material Science, Center of Dental

b Lithoz GmbH, Vienna, Austria

c Department of Mathematical Statistics, University of Bern, Switzerland

d Master student, Center of Dental Medicine, University of Zurich, Switzerland 


\section{Acknowledgements}

The authors express their thank to Falko Noack, Chistoph Giessmann, Albert Trottmann, Andrea Patrizi and Raphael Laue for their help in the fabrication procedures. The current study is part of and in parts identical with the master's thesis "Load-bearing capacity of ultra-thin occlusal veneers on molars, comparing 3D-printed zirconia, CAD/CAM-fabricated zirconia and heat-pressed lithium disilicate ceramic reconstructions: an in-vitro study" by the co-author Olivia Birrer, performed at the University of Zurich, Switzerland, under the supervision of Alexis loannidis and Christoph Hämmerle.

\section{Declaration of Interest}

We wish to confirm that there are no known conflicts of interest associated with this publication and there has been no significant financial support for this work that could have influenced its outcome. We confirm that the manuscript has been read and approved by all named authors and that there are no other persons who satisfied the criteria for authorship but are not listed. We further confirm that the order of authors listed in the manuscript has been approved by all of us.

We confirm that we have given due consideration to the protection of intellectual property associated with this work and that there are no impediments to publication, including the timing of publication, with respect to intellectual property. In so doing we confirm that we have followed the regulations of our institutions concerning intellectual property.

We understand that the Corresponding Author is the sole contact for the Editorial process (including Editorial Manager and direct communications with the office). He is responsible for communicating with the other authors about progress, submissions of revisions and final approval of proofs. We confirm that we have provided a current, correct email address which is accessible by the Corresponding Author and which has been configured to accept email from alexis.ioannidis@zzm.uzh.ch. 


\section{Abstract}

Objectives: The load-bearing capacity of ultra-thin occlusal veneers made of 3D-printed zirconia were compared to the ones obtained by fabricating these reconstructions by CAD/CAM milling zirconia or heat-pressing lithium-disilicate.

Methods: On 60 extracted human molars, the occlusal enamel was removed and extended into dentin. Occlusal veneers of $0.5 \mathrm{~mm}$ thickness were digitally designed. The specimens were divided into 3 groups ( $n=20$ each) differing in the restorative material and the fabrication technique of the occlusal veneer. (1) 3DP: 3D-printed zirconia (Lithoz); (2): CAM: milled zirconia (Ceramill Zolid FX); (3) HPR: heat-pressed lithium disilicate (IPS e.max Press). After conditioning procedures, the restorations were adhesively bonded onto the conditioned tooth. Thereafter, all specimens were aged in a chewing simulator by exposure to cyclic fatigue and temperature variations. Subsequently the specimens were statically loaded and the load which was necessary to decrease the maximum load by $20 \%$ and initiate a crack $\left(F_{\text {initial }}\right)$ and the load which was needed to fracture the specimen $\left(F_{\max }\right)$ were measured. Differences between the groups were compared applying the Kruskal-Wallis (KW) test and the Wilcoxon-Mann-Whitney-Test (WMW: $p<0.05)$.

Results: The median $F_{\text {initial }}$ values for the groups 3DP, CAM and HPR were 1'650 N, 1'250 N and 500 $\mathrm{N}$. The differences between all three groups were statistically significant $(\mathrm{KW}: \mathrm{p}<0.0001)$. The median $\mathrm{F}_{\max }$ values amounted to 2'026 $\mathrm{N}$ for the group 3DP, 1'500 $\mathrm{N}$ for the group CAM and 1'555 $\mathrm{N}$ for the group HPR. Significant differences were found between 3DP and CAM (WMW: $p=0.0238$ ).

Significance: Regarding their load-bearing capacity, 3D-printed or milled zirconia as well as heatpressed lithium disilicate can be recommended as restorative material for ultra-thin occlusal veneers to prosthetically compensate for occlusal tooth wear. Despite statistically significant differences between the restoration materials, all load-bearing capacities exceeded the clinically expected normal bite forces. 


\section{Introduction}

Extensive tooth wear and/or erosive substances can result in loss of occlusal tooth substance. A prosthetic rehabilitation may be necessary to compensate the lost tooth substance and to eliminate the associated symptoms. Traditional treatment concepts propose to restore the worn dentition by means of full-crown restorations [1]. However, these concepts involve a further loss of healthy tooth substance by extensive preparation of the already impeded dentition [2]. Nowadays, ultra-thin occlusal veneers represent an appropriate treatment alternative in cases of extensive erosive or abrasive tooth substance loss [3]. Zirconia and lithium disilicate ceramic are both eligible materials for these kind of minimally invasive restorations [4-6].

With the introduction of computer-aided design/computer-aided manufacturing (CAD/CAM), the processing of the high-strength ceramic zirconia has become possible [7-9]. Zirconia reconstructions are usually milled out of pre-fabricated zirconia blanks by subtractive manufacturing. The milling process is commonly performed using a pre-sintered condition of the zirconia blank. In this state, zirconia has a low inherent strength and the fabrication of ultra-thin reconstructions can be challenging [6]. More lately, additive manufacturing techniques have been introduced to fabricate high strength ceramics by lithography-based ceramic manufacturing (LCM) [10]. This technique allows to fabricate complex three-dimensional structures with high accuracy [10]. By 3D printing zirconia, restorations in a high resolution and thin walls can be produced [11]. The fabrication of heat-pressed lithium disilicate reconstructions exhibiting thin wall thicknesses is a regular procedure and showed a good reliability [트, 12].

Both materials, zirconia and lithium disilicate, demonstrate an improved fracture toughness and higher flexural strength in comparison to conventional glass ceramics [13, 14]. A study compared the mechanical performance of occlusal veneers made out of either zirconia or lithium disilicate [15]. It was found that being bonded to dentin, the load-bearing capacity of lithium disilicate is about $57 \%$ of the load-bearing capacity of zirconia [15]. Accordingly, another study revealed a median load-bearing capacity of 2'493 $\mathrm{N}$ for zirconia and 1'165 $\mathrm{N}$ for lithium disilicate restorations in $0.5 \mathrm{~mm}$ thickness when 
bonded to dentin [16]. The results of both groups surpassed the suggested fracture toughness for posterior reconstructions by far [17]. Thus, both materials are mechanically appropriate for the use as ultra-thin occlusal veneers in the posterior region.

Up to now, there is no study available in the literature, comparing the mechanical performance of 3Dprinted occlusal veneers made of zirconia to more traditionally applied fabrication techniques using conventional ceramic materials. Therefore, the objective of this study was to test whether the loadbearing capacity of ultra-thin 3D-printed zirconia occlusal veneers on molars exhibit differing loadbearing capacities if compared to CAD/CAM milled zirconia or pressed lithium-disilicate ceramic reconstructions. 


\section{Material and Methods}

\subsection{Groups}

The groups differed in the used restorative material (Table 1) and the fabrication technique. In total, 3 groups of 20 specimens each ( $n=20$ ) were included: (1) "3DP": 3D-printed occlusal veneers made out of zirconia (Lithoz, Vienna, Austria); (2) "CAM": CAD/CAM-fabricated occlusal veneers milled out of zirconia (Ceramill Zolid FX; Amann Girrbach, Pforzheim, Germany); (3) "HPR”: heat-pressed occlusal veneers made out of lithium-disilicate ceramic (IPS e.max press; Ivoclar Vivadent, Schaan, Liechtenstein).

\subsection{Specimen preparation}

In total, 60 extracted and intact human molars were inserted in an acrylic hollow cylinder made out of acrylic glass. The apical part of the tooth was embedded in self-curing resin (Technovit 4071; Kulzer, Wasserburg, Germany). To create typical defects for attrition or erosion, the occlusal enamel of the crown was removed until exposure of the dentin. Furthermore, fissures were slightly opened and sharp edges were rounded off. The specimens were randomly allocated to one of the study groups. During the complete study, the specimens were stored in distilled water.

\subsection{Scanning procedures and restoration design}

An optical impression of the prepared tooth was taken by means of a desktop scanner (Identica 3D Scanner; Dental Concept Systems, Ulm, Germany) and transmitted to a design software (3Shape software; Copenhagen, Denmark). Occlusal veneers were designed with a homogenous thickness of $0.5 \mathrm{~mm}$ (Figure 1).

\subsection{Fabrication of the restorations}

According to the group allocation, the ceramic restorations were fabricated. 


\subsubsection{Group 3DP: fabrication procedures}

The occlusal veneers of the group 3DP were fabricated by means of the Lithography-based Ceramic Manufacturing (LCM) process, which is based on the concept of photopolymerization (Figure 2) [18, 19]. Ceramic powder was dispersed into a mixture of photo-curable monomers to create the ceramic slurry (LithaCon 3Y 610 white; Lithoz, Vienna). The materials processed by LCM-technology were slurries comprising a photopolymerizable monomer mixture (dynamic viscosity at $20^{\circ} \mathrm{C}$ is $43 \mathrm{~Pa} \mathrm{~s}$ ) filled with various types of ceramic powder $\left(3 \mathrm{~mol} \% \mathrm{Y}_{2} \mathrm{O}_{3}\right.$ stabilized $\mathrm{ZrO}_{2}$ in a purity of 99.9\%) in a concentration of $40-60 \mathrm{Vol} \%$. A thin layer of this slurry was automatically coated onto the vat, which is an assembly with transparent glass bottom. Thereafter, the building platform approached the vat, only leaving a small gap of $25 \mu \mathrm{m}$, which was filled with slurry. This gap correlates to the thickness of an individual layer in the green part. Consecutively, the photosensitive compounds comprised within this slurry were cured by selective exposure with blue light (wavelength $460 \mathrm{~nm}$ ). Where this light hit the ceramic-filled slurry, the monomers photopolymerized into a 3-dimensional network, which then acted as a cage for the ceramic filler. After completing the layer, the building platform was elevated and the whole sequence was repeated all over again. The occlusal veneers were layered perpendicular to the tooth axis. The scaling factor was in $\mathrm{XY}$-direction $1.358 \times$ and in Z-direction $1.370 \times$ to compensate for the sinter-shrinkage. After the layer-by-layer structuring using the CeraFab 7500-system (Lithoz, Vienna) the green parts were cleaned from the excess slurry by using compressed air and an appropriate solvent (LithaSol 20, Lithoz) capable of dissolving the slurry without damaging the cured structure. Postprocessing involved the debinding of the green part in which the organic photopolymer matrix was removed through pyrolysis at stepwise raising temperatures between 115 and $11^{\prime} 450^{\circ} \mathrm{C}$. Then, the resulting white parts were sintered in a high-temperature $\left(1^{\prime} 450{ }^{\circ} \mathrm{C}, 2\right.$ hours) furnace (Nabertherm HTCT 08/16; Nabertherm, Lilienthal, Germany) to fully density (99.3\%). Thereafter, the supporting structure was cautiously removed (Figure 3). 


\subsubsection{Group CAM: fabrication procedures}

The ceramic restorations of the group CAD were directly milled out of pre-fabricated zirconia discs (Ceramill Zolid FX; Amann Girrbach) using a 5-axis milling machine (Ceramill Motion2 5x; Amann Girrbach). Thereafter, the restorations were sintered to full density according to the manufacturer's instructions (Ceramill Therm S; Amann Girrbach).

\subsubsection{Group HPR: fabrication procedures}

For the ceramic restorations of the group HPR, first, a PMMA template was milled out of a prefabricated ingot (Ceramill PMMA; Amann Girrbach) by means of a 5-axis milling machine (Ceramill Motion2 5x; Amann Girrbach). The templates were then used to produce pressed lithium disilicate restorations applying the "lost-wax and press-technique" and following the manufacturer's instructions. For this purpose, the PMMA-templates were fixed by a wax sprue (IPS Multi Wax Pattern Form A; Ivoclar Vivadent) and vested (IPS PressVEST Premium; Ivoclar Vivadent) into a mold. In an oven (KaVo EWL 5645; KaVo, Kloten, Switzerland), the vested templated was heated to complete dissolution: rate of $5^{\circ} \mathrm{C} \mathrm{min}^{-1}$ from room temperature to $850^{\circ} \mathrm{C}$ (holding time $60 \mathrm{~min}$ ). Thereafter, into the resulting void, lithium-disilicate ceramic (IPS e.max Press; Ivoclar Vivadent) was heat-pressed in a heat-pressing sintering-oven (Programat EP 5010; Ivoclar Vivadent): rate $60^{\circ} \mathrm{C} \min ^{-1}$ from $700^{\circ} \mathrm{C}$ to $898^{\circ} \mathrm{C}$ (holding time $25 \mathrm{~min}$ ). After cooling, the restorations were carefully devested and cleaned from the investing material by air-abrasion $\left(50 \mu \mathrm{m} \mathrm{Al}_{2} \mathrm{O}_{3}\right.$; Cobra, Renfert $\mathrm{GmbH}$, Hilzingen, Germany) at a pressure of 2 bar. The surface was glazed and again placed into the sintering-oven.

\subsection{Cementation protocols}

The conditioning procedure of the inner surface of the ceramic restoration varied according to the groups. In group HPR, etching for $20 \mathrm{~s}$ with 5\% hydrofluoric acid (IPS ceramic etching gel; Ivoclar Vivadent) followed by water-spraying and air-drying. In groups 3DP and CAM, air-abrasion was applied to the inner parts (Rocatec Plus $30 \mu \mathrm{m}, 2.5$ bar; 3M ESPE, Seefeld, Germany). In all groups, a silane 
(Monobond Plus; Ivoclar Vivadent) was used and gently air-dried after $60 \mathrm{~s}$. The enamel and the dentin of all specimens were etched with $35 \%$ phosphoric acid for $30 \mathrm{~s}$ (Ultraetch; Ultradent, Utah, USA). The surface was thereafter water-sprayed (30 s) and air-dried. An adhesive (Syntac Primer/Syntac Adhesive; Ivoclar Vivadent) was used for the dentinal parts. A bonding agent (Heliobond; Ivoclar Vivadent) was applied to the tooth surface and to the ceramic restorations and after $20 \mathrm{~s}$ gently airblown. The restorations were adhesively cemented using a dual-curing resin cement (Variolink Esthetic DC; Ivoclar Vivadent). After removal of excess cement, light-curing was performed (6 x $40 \mathrm{~s})$.

\subsection{Aging procedures}

A chewing simulator [20] was used to age the specimens by a vertical indenter (rounded tip of $\emptyset 8 \mathrm{~mm}$ ) executing a vertical movement of $1 \mathrm{~mm}$ in a perpendicular direction to the occlusal plane (1'200'000 cycles of $49 \mathrm{~N}$ force at $1.67 \mathrm{~Hz}$ loading frequency) and thermo-cycling $\left(5-55^{\circ} \mathrm{C}\right.$ and a dwelling time of $120 \mathrm{~s}$ ). After aging, the specimens were evaluated under a stereomicroscope (magnification $1.25 \times$ ) to check for integrity.

\subsection{Static loading}

The aged specimens were loaded in a universal testing machine (Zwick / Roell Z010; Zwick, Ulm, Germany) to test the static fracture load. An indenter axially hit the occlusal surface of the specimen with a crosshead speed of $1 \mathrm{~mm} / \mathrm{min}$. The load which was necessary to initiate a crack $\left(F_{\text {initial }}\right)$ and the load which was needed to completely fracture the specimen $\left(F_{\max }\right)$ were measured. The type of failure was specified under a stereomicroscope (9× magnification; Leica DFC300 FX; Wetzlar, Germany) and on photographs. The following scores were categorized: (1) score $0=$ no visible fracture, (2) score $1=$ cohesive fracture within the restoration, (3) score $2=$ cohesive fracture of the restoration and of the cement layer, (4) score 3 = fracture of the restoration-cement-tooth complex.

\subsection{Statistical analysis}

The metric variables $\left(F_{\text {initial, }} F_{\max }\right)$ were described with mean, median, standard deviations, quartiles, minimum and maximum. They were compared using a non-parametric Kruskal-Wallis test (KW). The 
exact p-values were calculated for the pair-wise comparisons between the groups using the WilcoxonMann-Whitney-Test (WMW), applying the Bonferroni correction for the multiple testing.

The categorical variables (failure scores) were summarized by counts and proportions of the categories and compared applying the Chi-squares test with exact determination of the p-value. 


\section{Results}

\subsection{Fatigue resistance}

All specimens of all groups survived the thermo-mechanical aging without any technical complication. Therefore, all specimens were able to be further loaded until fracture in the static loading test.

\subsection{Load-bearing capacity}

The median $F_{\text {initial }}$ values (and first Q1 and third Q3 quartiles) for the groups 3DP, CAM and HPR were 1'650 N (Q1: 1200, Q3: 1900), 1'250 N (Q1: 1'050, Q3: 1'400) and 500 N (Q1: 143, Q3: 1'100) (Table 2, Figure 4). In group 3DP values ranged between 250 and 1'900 N. The minimum value in group CAM was $100 \mathrm{~N}$, whereas 1 '800 $\mathrm{N}$ was the highest reached $\mathrm{F}_{\text {initial }}$ value. The range in group HPR was between 40 and 1'700 N. All three groups showed statistically significant differences for $F_{\text {initial }}(\mathrm{KW} p<$ 0.0001 ) between each other. The exact $p$-values amounted $p=0.0387$ (WMW) for the comparison 3DP - CAM, $p<0.003$ for the comparison 3DP - HPR and $p=0.0051$ for the comparison CAM - HPR.

The median (and first Q1 and third Q3 quartiles) of the $F_{\max }$ values were: 2'025 N (Q1: 1'664, Q3: 2'184) for 3DP, 1'500 N (Q1: 1'423, Q3: 1'907) for CAM and 1'555 N (Q1: 1308.5, Q3: 2050) for HPR (Table 2, Figure 5). The $\mathrm{F}_{\max }$ values of group 3DP ranged between 1'189 and 2'808 N, whereas the minimal and maximal values of group CAM were 952 and 2'879 $\mathrm{N}$ respectively. In the group HPR the minima and maxima were 795 and 2'337 N. The Kruskal-Wallis test showed significant differences between the groups $(p=0.0238)$. The significances were found for the comparison 3DP-CAM (exact p-value WMW: $p=0.0336$ )

\subsection{Failure types}

The distribution of failure types was analyzed with a Chi-square test (Figure 6). No group showed Score 0 fractures. Score 1 fractures were detected in 15\% of the HPR specimens. $85 \%$ of the HPR specimens were attributed to Score 2 and $5 \%$ to Score 3 fractures. In the groups 3DP and CAM, half of the specimens showed Score 2 and half of the specimens Score 3 fractures. Significant differences were 
found between the three groups $(p=0.0016)$. Group HPR showed a higher incidence of score 1 fractures and a lower incidence of score 3 fractures than statistically expected. 


\section{Discussion}

For the first time, the LCM technique was applied for the fabrication of 3D-printed zirconia restorations. The present investigation showed that 3D-printed zirconia ultra-thin occlusal veneers exhibited similar or higher load-bearing capacities as compared to heat-pressed lithium disilicate or CAD/CAM milled zirconia occlusal veneers.

All tested specimens survived aging procedures without any technical complication, indicating that 3Dprinted zirconia, milled zirconia and heat-pressed lithium disilicate restorations in a thickness of 0.5 mm may withstand normal clinical conditions. The artificial aging included 1'200'000 dynamic loading cycles of $49 \mathrm{~N}$ in a frequency of $1.67 \mathrm{~Hz}$ with thermo-cycling between $5-55^{\circ} \mathrm{C}$ and was reported to simulate 5 years of clinical service [21-23]. Chewing forces, however, are known to be higher than 49 $\mathrm{N}$ and may vary from 200 to $540 \mathrm{~N}$ [24]. In patients suffering from bruxism, values of up to $800 \mathrm{~N}$ were measured [24]. Considering the median $F_{\text {initial }}$ values ranging from $500 \mathrm{~N}(\mathrm{HPR})$ to 1'250 N (CAM) and 1 '650 N (3DP), it may be assumed that all the tested restorative materials would withstand regular clinical conditions.

In the present study, the measured $F_{\text {initial }}$ and $F_{\max }$ values in each group were higher than the flexural strength values provided by the manufacturers of the tested restoration materials. Flexural strength of 3D-printed zirconia in group 3DP is reported to be $800 \mathrm{MPa}$, the zirconia in group CAM exhibits 700 $\mathrm{MPa}$, whereas for heat-pressed lithium disilicate ceramic in group HPR $470 \mathrm{MPa}$ are expected. In this study, however, the load-bearing capacity of the specimens was tested, which includes the entire tooth-cement-restoration complex and therefore resulted in much higher values. Apparently, the sequence of median $F_{\text {initial }}$-values with 1'650 N (3DP), 1'250 N (CAM) and $500 \mathrm{~N}$ (HPR) met the expectations derived from the mechanical properties provided by the manufacturers. $F_{\text {initial }}$ represents the load which is needed to form a crack in the tested specimen. Thus, the crack formation started at the lowest loads in the lithium disilicate restorations, while the zirconia restorations showed a crack formation at higher states. This is in accordance with studies showing that zirconia has a better mechanical performance than lithium disilicate ceramic $[\underline{8}, \underline{14}$. Despite the high median capability of 
3D printed zirconia to withstand loads which lead to crack formation, the deviation of the recorded values was high. This might be attributed to the fabrication method of $3 \mathrm{D}$ printed restorations which involves a postprocessing by debinding the green part from the organic photopolymer matrix. Therefore, future developments should aim to investigate the influence of postprocessing on the consistency of the mechanical performance of 3D printed zirconia. In all groups, a complete fracture of the specimens $\left(F_{\max }\right)$ was observed at much higher values with medians of 2'026 $\mathrm{N}$ for 3DP, followed by 1'555 $\mathrm{N}$ for HPR and 1'500 N for CAM. The greatest increase was observed in the specimens with lithium disilicate ceramic occlusal veneers. It may be hypothesized that the strong adhesive bond between lithium disilicate and the abutment tooth is able to compensated the inferior mechanical property of the material compared to the zirconia restorations and positively influenced the loadbearing for lithium disilicate occlusal veneers thereby [25].

The specimens with 3D printed zirconia showed the same fracture patterns as the ones with milled zirconia. In both groups with zirconia, half of the fractures occurred within the restoration and the cement layer (score 2) and half of the fractures affected the entire restoration-cement-tooth complex (score 3). In contrast, for lithium disilicate $95 \%$ of all specimens showed fractures within the restorative material (score 1) or the restorative material and the cement layer (score 2). Score 1 and 2 fractures indicate that static loading forces are able to break the restoration and the adhesive bond but not the natural tooth itself. Score 3 fractures, however, involve a fracture of the entire restoration-cementtooth complex and thus indicate that the mechanical resistance of the restorative material surpasses the mechanical strength of the tooth itself. With zirconia being a restorative material showing higher flexural strength than lithium disilicate, the distribution of fracture patterns seems reasonable.

In this study, a non-translucent zirconia was used for the production of the 3DP specimens. Regarding the optical properties, this type of zirconia may not be an ideal restoration material for occlusal veneers. The optical and mechanical properties of zirconia are related to the chemical composition (REF 31034947). Conventional zirconia with $3 m o l \% \quad \mathrm{Y}_{2} \mathrm{O}_{3}$ stabilized $\mathrm{ZrO}_{2}$ showed excellent mechanical properties but are known to be opaque [26]. The translucency of zirconia was increased by a change in the percentages of Yttria and Alumina, the grain size, the use of different dopants and 
stabilizers [27-29]. By adapting the chemical composition of zirconia intermediate physical properties were obtained ranging between conventional zirconia and lithium disilicate [28, $\underline{30]}$. The comparison of two zirconia materials with differing chemical compositions may be seen as a limitation of the present study. The aim of the present investigation, however, was to present a proof of principle for the processing and mechanical performance of 3D printed occlusal zirconia veneers, as this method has not been approved by other studies yet.

For the minimally invasive reconstruction of the worn posterior dentition, high translucent milled zirconia or heat-pressed lithium disilicate are both materials that can be recommended clinically. Occlusal veneers made by 3D printing zirconia, showed promising results regarding their mechanical properties. Further efforts have to be made to increase the translucency of zirconia used for 3Dprinting by the LCM technique. 


\section{Conclusions}

Regarding their load-bearing capacity, CAD/CAM 3D-printed or subtractive CAD/CAM milled zirconia as well as heat-pressed lithium disilicate can be recommended to fabricate ultra-thin occlusal veneers

to prosthetically compensate for occlusal tooth wear. Despite statistically significant differences between the restoration materials, all load-bearing capacities exceeded the clinically expected normal bite forces.

\section{Conflict of Interest}

The study was supported with materials from Lithoz, Amann Girrbach and Ivoclar Vivadent. Lithoz and Amann Girrbach were involved in the production of the specimens.

\section{Acknowledgements}

\section{Blinded}




\section{Tables and Figures}

Table 1 - Restorative materials and respective compositions for the groups 3DP, CAM and HPR.

\begin{tabular}{|c|c|c|}
\hline Group & Restorative material & Chemical composition \\
\hline 3DP & Zirconia (Lithoz, Wien, Austria ) & $\begin{array}{l}\mathrm{ZrO}_{2}+\mathrm{HfO}_{2}+\mathrm{Y}_{2} \mathrm{O}_{3}+\mathrm{Al}_{2} \mathrm{O}_{3}(99.95 w t \%), \mathrm{Y}_{2} \mathrm{O}_{3}(5,4-5,8 w t \%), \mathrm{Al}_{2} \mathrm{O}_{3}(0.15- \\
0.35 \mathrm{wt} \%),\end{array}$ \\
\hline CAM & Zirconia (Ceramill zolid FX, Amann Girrbach, Pforzheim Germany) & $\begin{array}{l}\mathrm{ZrO}_{2}(90.4-94.5 \mathrm{wt} \%), \mathrm{Y}_{2} \mathrm{O}_{3}(4-6 \mathrm{wt} \%), \mathrm{HfO}_{2}(1.5-2.5 \mathrm{wt} \%), \mathrm{Al}_{2} \mathrm{O}_{3}(0-0.3 \\
w t \%), \mathrm{Er}_{2} \mathrm{O}_{3}(0-0.5 \mathrm{wt} \%), \mathrm{Fe}_{2} \mathrm{O}_{3}(0-0.3 \mathrm{wt} \%)\end{array}$ \\
\hline HPR & Lithium disilicate ceramic (IPS e.max Press; Ivoclar Vivadent, Schaan, Liechtenstein) & $\begin{array}{l}\mathrm{SiO}_{2}(57-80 w t \%), \mathrm{Li}_{2} \mathrm{O}(11-19 w t \%), \mathrm{K}_{2} \mathrm{O}(0-13 \mathrm{wt} \%), \mathrm{P}_{2} \mathrm{O}_{5}(0-11 \mathrm{wt} \%), \\
\mathrm{ZrO} \mathrm{C}_{2}(0-8 \mathrm{wt} \%), \mathrm{ZnO}(0-8 \mathrm{wt} \%), \text { other oxides and ceramic pigments }(0- \\
10 \mathrm{wt} \%)\end{array}$ \\
\hline
\end{tabular}

Table $2-F_{\text {initial }}$ and $F_{\max }$ values for the groups 3DP, CAM and HPR with means and standard deviation, median, 1. quartiles (Q1), 3. quartiles (Q3), minima (min) and maxima (max). Values in Newton.

\begin{tabular}{|c|c|c|c|c|c|c|c|c|c|c|c|}
\hline \multirow[b]{2}{*}{ Group } & \multirow[b]{2}{*}{$\mathbf{n}$} & \multicolumn{5}{|l|}{ F initial } & \multicolumn{5}{|l|}{$F$ max } \\
\hline & & Mean \pm SD & Q1 & Median & Q3 & Range $\min$ to $\max$ & Mean \pm SD & Q1 & Median & Q3 & Range $\min$ to $\max$ \\
\hline $3 \mathrm{DP}$ & 20 & $1^{\prime} 583 \pm 542$ & 1'200 & $1^{\prime} 650$ & $1 ' 900$ & 250 to $2^{\prime} 800$ & $1^{\prime} 928 \pm 396$ & $1 ' 665$ & $2^{\prime} 026$ & 2'184 & 1'189 to 2 ' 808 \\
\hline CAM & 20 & $1 ' 215 \pm 407$ & $1 ' 050$ & $1 ' 250$ & $1 ' 400$ & 100 to $1^{\prime} 800$ & $1 ' 635 \pm 410$ & $1 ' 423$ & $1 ' 500$ & 1'907 & 952 to $2{ }^{\prime} 879$ \\
\hline HPR & 20 & $662 \pm 568$ & 143 & 500 & 1'100 & 40 to $1^{\prime} 700$ & $1^{\prime} 614 \pm 422$ & 1'309 & 1'555 & 2'050 & 795 to 2337 \\
\hline
\end{tabular}


Figure 1 - Specimen and digitally designed semi-transparent depicted restoration from (a) lateral and (b) latero-occlusal.

Color should be used in print

(a)

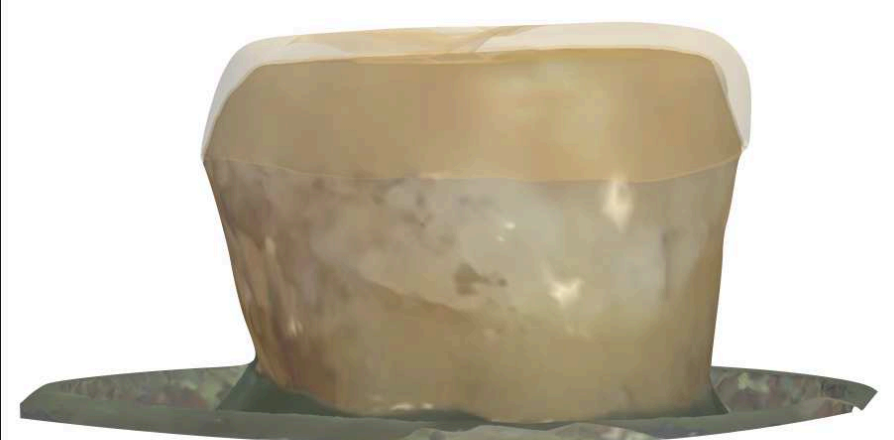

(b)

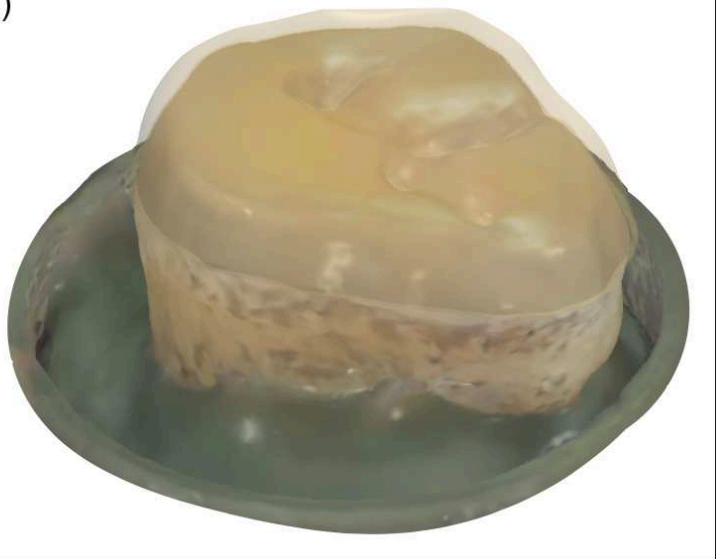


Figure 2 - Schematic drawing of the 3D printer, producing the occlusal veneers of group 3DP with the Lithography-based Manufacturing process. In this process, LED light of $460 \mathrm{~nm}$ wavelength (1) hits a digital micro mirror device (2). In this device, micro mirrors can be positioned in an activated or in a deactivated position. By activating or deactivating the mirrors, light can be selectively transmitted to the vat (3). The vat itself is filled with a slurry of ceramic powder (white symbols) dispersed in a mixture of photo-curable monomers (blue symbols) (4). Where the light hits the ceramic-filled slurry, the monomers photo-polymerize into a 3-dimensional network, which then acts as a cage for the ceramic filler. The building-platform takes up the 3-dimensional network layer by layer.

\section{Color should be used in print}

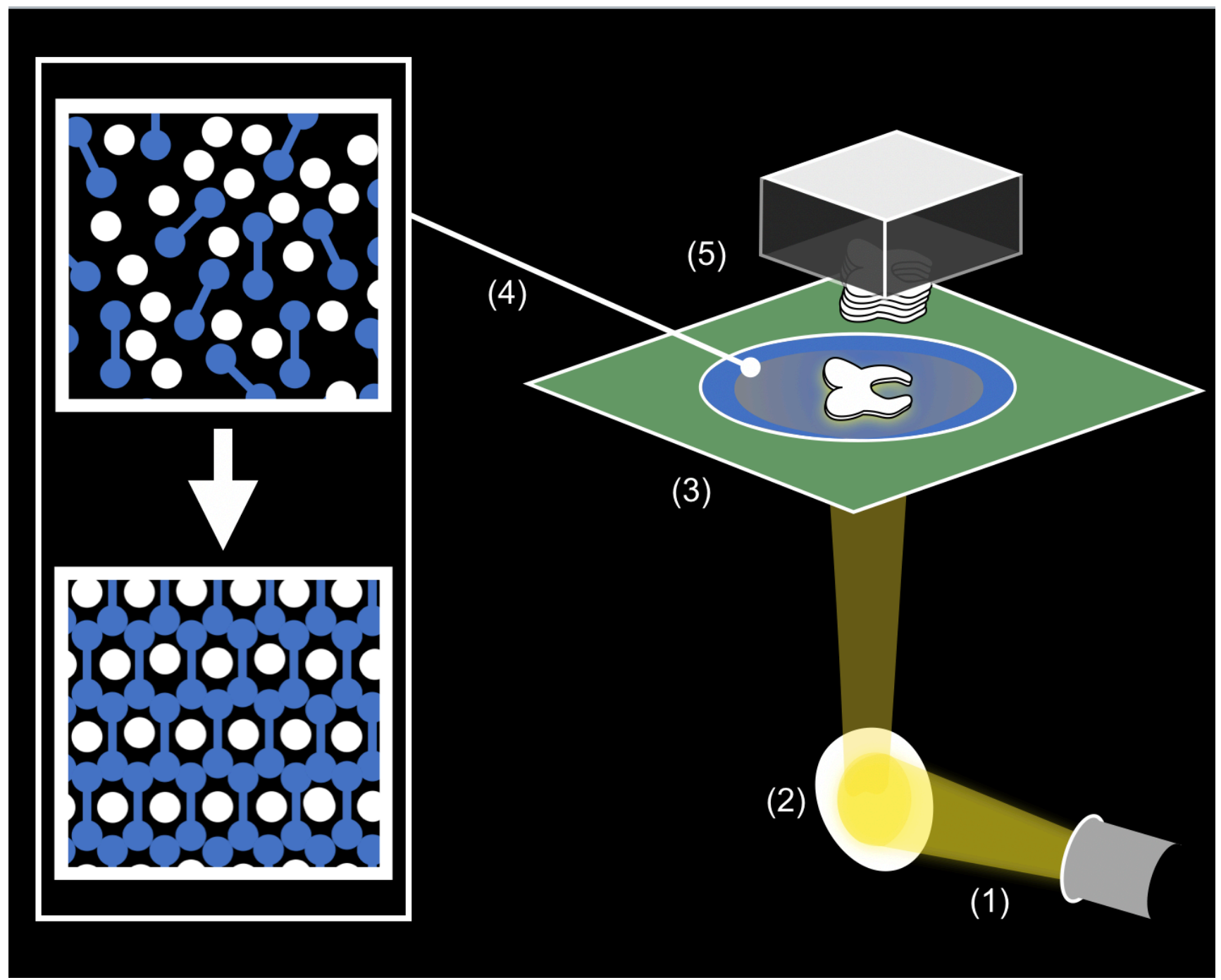


Figure 3 -3D-printed occlusal veneer before removing the support structures resulting from the printing process with (a) view from occlusal and (b) view on the inner surface. 3D-printed occlusal veneer (c) after having removed the supporting structure.

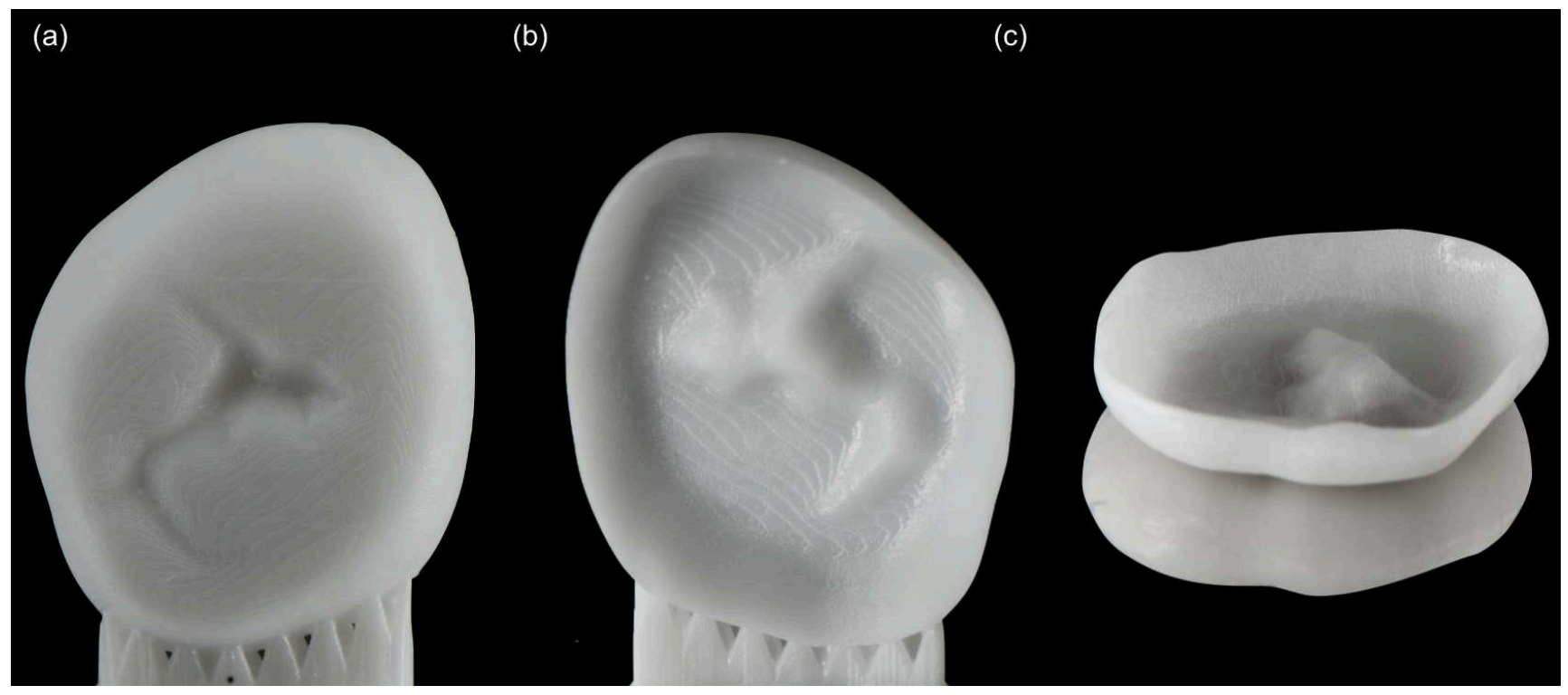


Figure 4 - Box plots for $F_{\text {initial }}$ values of the groups 3DP, CAM and HPR with significant differences marked with a dashed red bar and with the given exact p-values of the Wilcoxon-Mann-Whitney-Test.

\section{Color should be used in print}

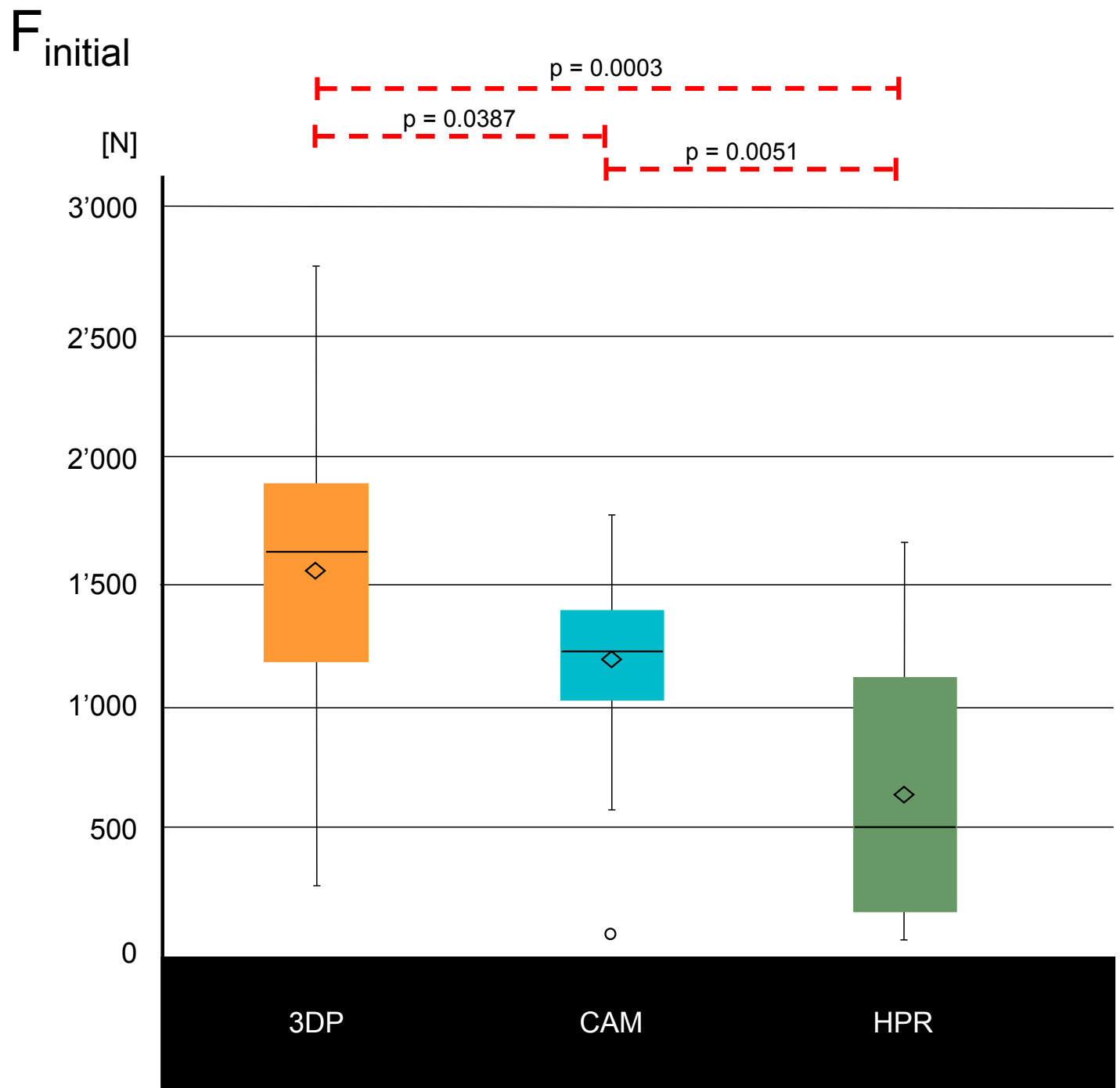


Figure 5 - Box plots for $F_{\max }$ values of the groups 3DP, CAM and HPR with significant differences marked with a dashed red bar and with the given exact p-value of the Wilcoxon-Mann-Whitney-Test.

\section{Color should be used in print}

$F_{\max }$

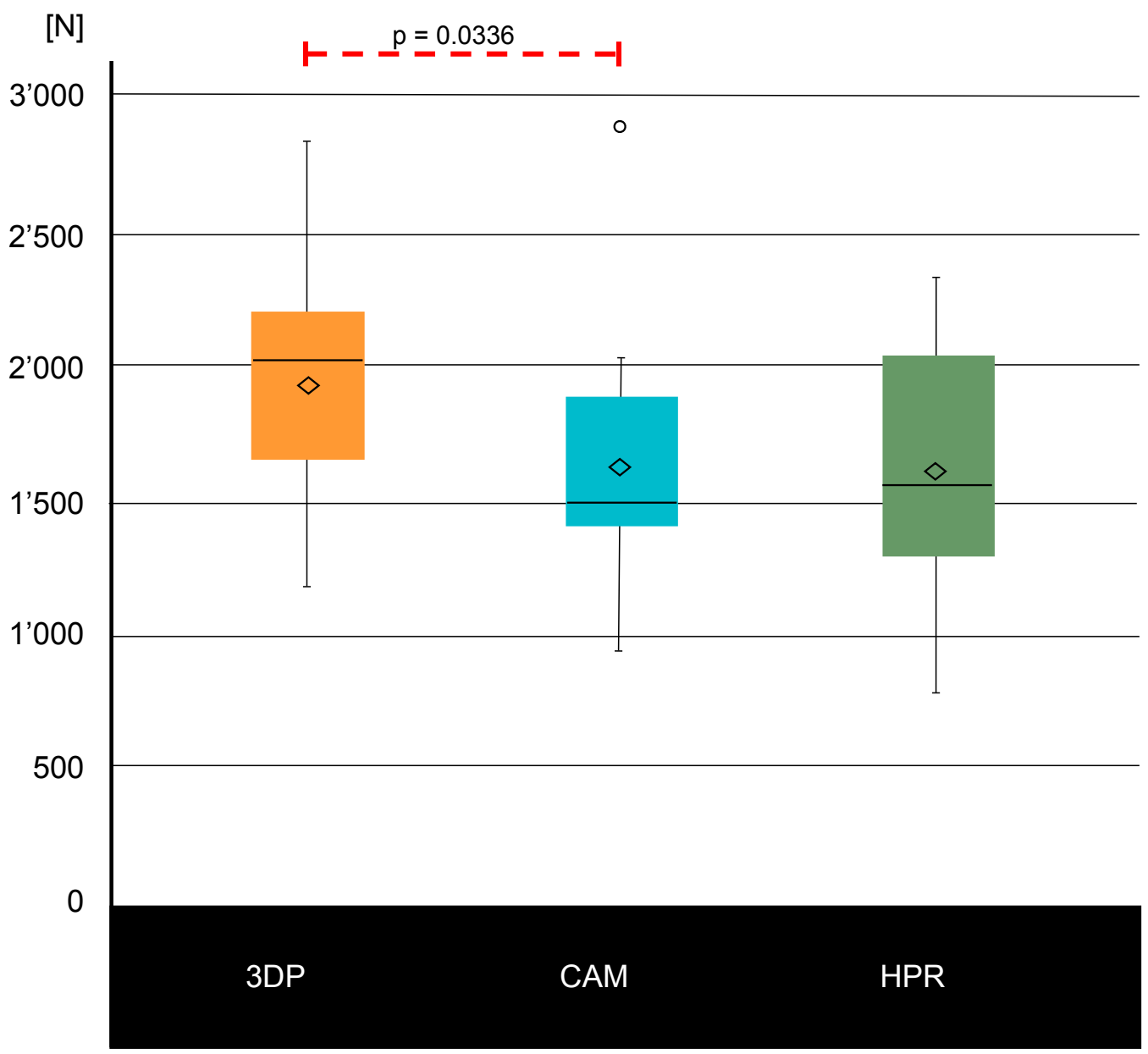


Figure 6 - Distribution of failure types for the groups 3DP, CAM and HPR. No visible fracture (score 0 ) was not seen in any of the groups. For the cohesive fracture within the restoration (score 1), cohesive fracture of the restoration and of the cement layer (score 2) and fracture of the restoration-cementtooth complex (score 3) representative pictures and the distribution in $\%$ are depicted.

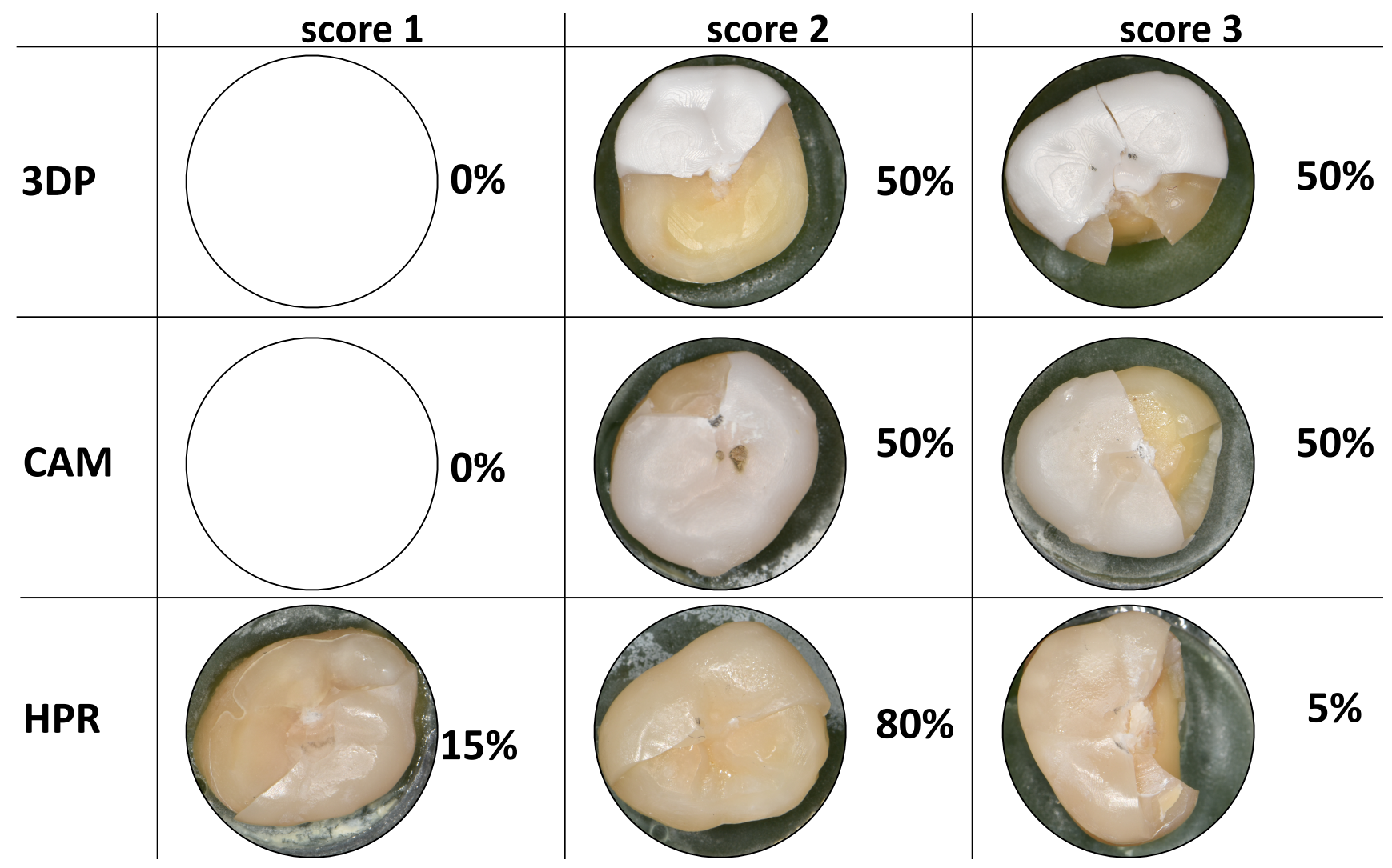




\section{References}

[1] Varma S, Preiskel A, Bartlett D. The management of tooth wear with crowns and indirect restorations. Br Dent J. 2018;224:343-7.

[2] Edelhoff D, Sorensen JA. Tooth structure removal associated with various preparation designs for posterior teeth. Int J Periodontics Restorative Dent. 2002;22:241-9.

[3] Muts EJ, van Pelt H, Edelhoff D, Krejci I, Cune M. Tooth wear: a systematic review of treatment options. J Prosthet Dent. 2014;112:752-9.

[4] Alkadi L, Ruse ND. Fracture toughness of two lithium disilicate dental glass ceramics. J Prosthet Dent. 2016;116:591-6.

[5] Guess PC, Selz CF, Steinhart YN, Stampf S, Strub JR. Prospective clinical split-mouth study of pressed and CAD/CAM all-ceramic partial-coverage restorations: 7-year results. Int J Prosthodont. 2013;26:21-5.

[6] loannidis A, Mühlemann S, Özcan M, Hüsler J, Hämmerle CH, Benic G. Ultra-thin occlusal veneers bonded to enamel and made of ceramic or hybrid materials exhibit load-bearing capacities not different from conventional restorations. Journal of the mechanical behavior of biomedical materials. 2019:433-40.

[7] Chevalier J. What future for zirconia as a biomaterial? Biomaterials. 2006;27:535-43.

[8] Denry I, Kelly JR. State of the art of zirconia for dental applications. Dent Mater. 2008;24:299-307.

[9] Tinschert J, Natt G, Hassenpflug S, Spiekermann H. Status of current CAD/CAM technology in dental medicine. Int J Comput Dent. 2004;7:25-45.

[10] Schwentenwein M, Homa J. Additive Manufacturing of Dense Alumina Ceramics. International Journal of Applied Ceramic Technology. 2014;12:1-7.

[11] Ebert J, Ozkol E, Zeichner A, Uibel K, Weiss O, Koops U, et al. Direct inkjet printing of dental prostheses made of zirconia. J Dent Res. 2009;88:673-6.

[12] Al-Akhali M, Chaar MS, Elsayed A, Samran A, Kern M. Fracture resistance of ceramic and polymer-based occlusal veneer restorations. Journal of the mechanical behavior of biomedical materials. 2017;74:245-50. 
[13] Guazzato M, Albakry M, Ringer SP, Swain MV. Strength, fracture toughness and microstructure of a selection of all-ceramic materials. Part I. Pressable and alumina glass-infiltrated ceramics. Dent Mater. 2004;20:441-8.

[14] Guazzato M, Albakry M, Ringer SP, Swain MV. Strength, fracture toughness and microstructure of a selection of all-ceramic materials. Part II. Zirconia-based dental ceramics. Dent Mater. 2004;20:449-56.

[15] Ma L, Guess PC, Zhang Y. Load-bearing properties of minimal-invasive monolithic lithium disilicate and zirconia occlusal onlays: finite element and theoretical analyses. Dent Mater. 2013;29:742-51.

[16] Maeder M, Pasic P, Ender A, Özcan M, Benic G, loannidis A. Load-bearing capacities of ultrathin occlusal veneers bonded to dentin. Journal of the mechanical behavior of biomedical materials. 2019;95:165-71.

[17] Körber K, Ludwig K. The maximum bite force as a critical factor for fixed partial dentures. Dent Labor. 1983;31:55-60.

[18] Schwentenwein M, Homa J. Additive manufacturing of dense alumina ceramics. International Journal of Applied Ceramic Technology. 2015;12:1-7.

[19] Homa J, Schwentenwein M. A novel additive manufacturing technology for high-performance ceramics. Ceram Eng Sci Proc2015. p. 33-40.

[20] Krejci I, Reich T, Lutz F, Albertoni M. [An in vitro test procedure for evaluating dental restoration systems. 1. A computer-controlled mastication simulator]. Schweiz Monatsschr Zahnmed. 1990;100:953-60.

[21] Bates JF, Stafford GD, Harrison A. Masticatory function--a review of the literature. 1. The form of the masticatory cycle. J Oral Rehabil. 1975;2:281-301.

[22] DeLong R, Douglas WH. An artificial oral environment for testing dental materials. IEEE Trans Biomed Eng. 1991;38:339-45.

[23] Steiner M, Mitsias ME, Ludwig K, Kern M. In vitro evaluation of a mechanical testing chewing simulator. Dent Mater. 2009;25:494-9.

[24] Bates JF, Stafford GD, Harrison A. Masticatory function - a review of the literature. III. Masticatory performance and efficiency. J Oral Rehabil. 1976;3:57-67.

[25] Lim MJ, Lee KW. Effect of adhesive luting on the fracture resistance of zirconia compared to that of composite resin and lithium disilicate glass ceramic. Restor Dent Endod. 2017;42:1-8. 
[26] Kwon SJ, Lawson NC, McLaren EE, Nejat AH, Burgess JO. Comparison of the mechanical properties of translucent zirconia and lithium disilicate. J Prosthet Dent. 2018;120:132-7.

[27] Jiang L, Liao Y, Wan Q, Li W. Effects of sintering temperature and particle size on the translucency of zirconium dioxide dental ceramic. J Mater Sci Mater Med. 2011;22:2429-35.

[28] Carrabba M, Keeling AJ, Aziz A, Vichi A, Fabian Fonzar R, Wood D, et al. Translucent zirconia in the ceramic scenario for monolithic restorations: A flexural strength and translucency comparison test. J Dent. 2017;60:70-6.

[29] Sulaiman TA, Abdulmajeed AA, Donovan TE, Ritter AV, Vallittu PK, Narhi TO, et al. Optical properties and light irradiance of monolithic zirconia at variable thicknesses. Dent Mater.

2015;31:1180-7.

[30] Zhang F, Reveron H, Spies BC, Van Meerbeek B, Chevalier J. Trade-off between fracture resistance and translucency of zirconia and lithium-disilicate glass ceramics for monolithic restorations. Acta biomaterialia. 2019;91:24-34. 